professional training of a hospital physician or for the vocational training of a general practitioner, and the plan stresses that training carried out within a specialty is not necessarily being undertaken as training for that specialty.

Until now recommendation of hospital posts by the Royal College of Physicians has been based simply on information provided by the hospital. In the new scheme every hospital seeking approval of its posts will be visited by a team of two physicians recommended by the Royal College of Physicians, the college's regional adviser, a representative of the Royal College of General Practitioners, and if possible the local postgraduate dean and the S.A.M.O.

There is unlikely to be serious criticism of the standards proposed in the report. Doubts will be centred on feasibility and enforcement. Will there be enough jobs throughout the country for the rising numbers of new graduates-over 3,000 a year in England and Wales by the end of this decade? There is a hint in the report of an expedient compromise when it states that "the criteria are not rigid: they should be seen as something to aim for and visiting teams will have to take local conditions into account...." High standards are unlikely to be achieved throughout the country by a policy of persuasion; experience in the U.S.A. has shown that hospital authorities rapidly revise their financial priorities when threatened with withdrawal of accreditation, and the same tough line should be taken here. The abuses of the provisional registration scheme were accepted without too much protest by everyone concerned because it required only one year's compulsory service. Once this period is extended to three or more years attitudes will be very different. Young doctors should not be expected to work in jobs which are educationally substandard-and they are unlikely to allow themselves to be forced to.

1 British Medical fournal, 1973, 1, 113.

2 Report of the Foint Committee on General Professional Training. London, Royal College of Physicians of London, and Royal College of General Practitioners, 1973. Price 10p.

\section{The Doctor's Attitude}

Faced with a patient in need of psychiatric help, a general practitioner could nowadays have access to a wide range of resources. They include treatment with drugs and other physical methods; various forms of psychotherapy, either individually or in groups; behaviour therapies; and treatment in a therapeutic community or a special unit.

But, while these are potentially obtainable, access to all of them except drug treatment is restricted either because outside large towns or teaching centres some forms of treatment may not be available, or because of an interminable waiting list. Some Cerberus, too, in the shape of a dissenting psychiatrist may guard the gates. Nor has it often been clearly said that "sectorization"-the rather rigid allotment of a defined area with its population and the practitioners serving it to a psychiatric team ${ }^{12}$-is a further restriction, though this system doubtless has many administrative advantages and works well if sensibly and flexibly applied.

Therefore, unless the practitioner lives in a favoured area or is himself determined and resourceful, he will deal largely with his local team of one or two psychiatrists. He may console himself, perhaps, if he practises in an area served by an eclectic psychiatrist, that the repertoire of therapies used will be broad and that each patient will be treated by the method generally thought to be most apt in the light of up-to-date scientific knowledge. That this confidence may be misplaced is suggested by a recent paper from Aberdeen by D. J. Pallis and B. E. Stoffelmayr. ${ }^{3}$ It shows that even eclectic psychiatrists may, because of their personalities and their training, have internal shackles that influence the treatment they prescribe.

Earlier work based on questionnaires has shown that the attitudes of psychiatrists to treatment can be fairly sharply categorized. N. Kreitman, ${ }^{4}$ for example, based his findings on replies from 78 psychiatrists working or in training at Bethlem and the Maudsley hospitals and identified "organic" and "psychological" groups. The organic group used medical disease models and predominantly physical methods of treatment. They discarded subjective and intuitive material. The other group had more interest in psychological factors and the exploration of unconscious motives. They relied more on interpersonal relations in therapy. Two factors that help to form these attitudes are the length of training in psychiatry and the amount of experience in general medicine before a psychiatric training is begun. The first is positively, the second negatively, correlated with a psychotherapeutic approach.

Later T. M. Caine and D. J. Smail ${ }^{5}$ used their own questionnaire and had 79 replies from psychiatrists (including 28 consultants) working in 14 British hospitals. Their analysis of attitudes to treatment yielded three fairly distinct components. The first and third resembled Kreitman's organic and psychological categories. The second component emphasized the importance of personal relations in the ward setting and group dynamics. Its emergence presumably reflects the interest in group methods, milieu therapy, and therapeutic communities that arose in the seven years between the two publications.

Both these earlier investigations included some attempt to relate the psychiatrists' attitude to treatment to factors in their personality. Such characteristics as "thinking-introversion," "neuroticism," and "tender-mindedness" were found more commonly among those with a psychotherapeutic orientation. "Thinking-introversion" was the dimension of personality, too, that $\mathrm{H}$. J. Walton ${ }^{6}$ found distinguished two groups of general practitioners attending postgraduate courses at Edinburgh - the physically orientated group from the psychologically orientated.

Pallis and Stoffelmayr, at Aberdeen, have used Caine's and Smail's "attitude to treatment questionnaire" again. They had replies from 42 out of 46 psychiatrists (including 19 consultants) working in one hospital region. They have employed two more questionnaires in an attempt to gauge social attitudes such as radical/conservative and tough/tender-minded. Significant positive correlations were found between a conservative social attitude and a preference for physical treatment. These psychiatrists, too, were more tough-minded. More radically inclined physicians not only favoured psychological methods of treatment but also chose a psychiatric career earlier than others.

The psychiatrists were asked to classify themselves according to their treatment attitudes and were given five choices-organic, psychotherapeutic, sociotherapeutic, eclectic, and uncommitted. Half declared themselves to be eclectic, and $31 \%$ thought themselves to be either socio- or psychotherapeutically inclined. These authors found no great differences between the two non-physical groups. Though 
the eclectics had higher scores for conservatism and toughmindedness, the difference did not reach significance. However, they had a significantly greater tendency to favour physical treatments, as did the $19 \%$ of the whole group who did not use any form of psychotherapy.

Though most of these results might be expected, they serve as a reminder that psychiatrists should be aware of associations between their social attitudes and the treatments they use. Disagreements, too, between psychiatrists about efficacy of various forms of treatment are not based on reason alone. They stem in part at least from deeper roots. Might not inquiries of this kind disclose useful categories in other fields-among surgeons, for example, or among general practitioners?

1 British fournal of Psychiatry, suppl. May 1973, p. 3.

2 Department of Health and Social Security, Report of the Professional Investigation into Medical and Nursing Practices on certain wards at Napsbury Hospital, nr. St. Albans, London, H.M.S.O., 1973 3 Pallis, D. J., and Stoffelmayr, B. E., British fournal of Medical Psychology,

- Kreitman, N., Fournal of Mental Science, 1962, 108, 317.

5 Caine, T. M., and Smail, D. J., The Treatment of Mental Illness: Science, Faith and the Therapeutic Personality, University of London Press, 1969. - Walton, H. J., British fournal of Psychiatry, 1966, 112, 1097.

\section{Neurogenic Ulcer}

"The first time that I had occasion to observe this appearance ... was in a man who had his skull fractured and was killed outright by one blow of a poker . . . The second time was . . . in a man who died a few hours after receiving a blow on his head, which fractured his skull likewise .... Afterwards I met with it in a soldier who had been hanged." So wrote John Hunter ${ }^{1}$ in his first presentation to the Royal Society in 1772 . He described "dissolution of the stomach at its great extremity" and stated that on squeezing the mucosa the blood was "found to pass out at the digested ends of the vessels, and appear like drops in the inner surface" (of the stomach). He ascribed this change to a post-mortem continuation of digestion which occurred once the body was rid of the "living principle."

Harvey Cushing's pathological description of the lesions ${ }^{2}$ came from three patients who had died from peritonitis one to four days after surgery to the cerebellum and mid-brain. Perforation had occurred from single or multiple acute ulcers in the oesophagus, along the lesser curvature of the stomach, or in the duodenum. In one of the cases other shallow ulcerations, or erosions, that had not perforated the bowel wall were seen. In another it was noted that there was no induration or indications of inflammatory reactions around the gastric perforations-evidence that the lesions were not reactivated chronic ulcers. Within the stomach there were widespread submucosal haemorrhages, and the mucosa was friable and easily torn. The lower portion of the oesophagus was also involved, the mucosa having longitudinal slits and submucosal haemorrhages. Under the microscope the pathologist found that punctate areas in the fundus were shallow haemorrhagic erosions, with oedema and heavy infiltration of polymorphonuclear leucocytes, which involved the whole wall of the stomach from mucosa to serosa.

From this account it can be seen that the lesion is extensive in the stomach and spreads also to the lower oesophagus and duodenum. The term gastromalacia ${ }^{2}$ has been applied to it, and this has its attractions as an all-embracing term for a pathological condition that is difficult to define. The presence of erosions, some of which are haemorrhagic, as well as acute ulcers which have perforated suggests that the one has progressed to the other, and that they both have a similar cause. Whether a patient presents clinically with acute gastrointestinal bleeding or perforation and peritonitis depends on the speed at which the lesion has evolved. The gastrointestinal lesion of neurogenic (Cushing's) ulcer is pathologically essentially the same as that seen after severe burns (or frostbite) and described by $T$. Curling. ${ }^{3}$

Cushing believed that gastromalacia was particularly associated with lesions of the cerebellum and hind brain. He himself also described cases occurring with malignant hypertension, and it is now clear that it may be associated with an acute lesion in any area of the brain. It occurs particularly after neurosurgery. Other intracranial causes include tumour, trauma, infection, haemorrhage, and ischaemia.

A recent paper from the neurosurgical unit of a children's hospital in Australia draws attention to its occurrence in childhood and infancy. ${ }^{4}$ The authors describe the experience of the unit over ten years, 16 cases occurring in that time. The children were aged 3 to 14 years, and in all cases gastrointestinal haemorrhage occurred within 7-10 days of intracranial surgery. The site of bleeding in the gut was the duodenum, stomach, or oesophagus, and the lesions were single or multiple. In more than half the cases the intracranial lesion was in the posterior fossa.

The clinical presentation in these children was a decline in consciousness associated with falling blood pressure, a difficult clinical picture to diagnose in a child recovering from neurosurgery. In some cases the abdominal symptoms became apparent as the patient recovered consciousness from the anaesthetic.

In this series half were treated conservatively by blood transfusion and all these made a complete recovery. Eight came to surgery, and six survived. Five of these had vagotomy and drainage and one partial gastrectomy. The best surgical procedure in these desperately ill patients would seem from this paper and another from Boston ${ }^{5}$ to be vagotomy and pyloroplasty. But surgical mortality is high, ranging from $25 \%$ to $40 \%$.

There has been much debate on the cause and pathogenesis of Cushing or neurogenic ulcers, but no clear answer has been reached. Whether or not gastric acid plays a part is also questioned. 67 However, increased vagal tone is probably one factor acting on the stomach, and a humoral mechanism that can be blocked by adrenalectomy may well be another. ${ }^{8}$ Once we understand the pathogenesis of gastric erosions, the cause of these acute gastric ulcers causing haemorrhage and perforation will become apparent. The reparative mechanism of the gastric mucosa in the turnover of gastric epithelial cells, and the factors which influence it, are clearly important in the pathogenesis of acute gastroduodenal lesions, including neurogenic ulcer. ${ }^{9}$

1 Hunter, J., Philosophical Transactions, 1772, 62, 77

2 Cushing, H., Surgery, Gynecology and Obstetrics, 1932, 55, 1

${ }^{3}$ Curling, T., Transactions of the Medical Society of London, 1842, 25, 260.

4 Lewis, E. A., British fournal of Surgery, 1973, 60, 279

Byrne, J. J., and Guardione, V. A., American fournal of Surgery, 1973, $125,464$.

6 Feldman, S., Burnbaum, D., and Behar, A. J., Fournal of Neurosurgery, $1961,18,661$.

7 Watts, C. C., and Clarke, K., Fournal of Neurosurgery, 1969, 30, 107.

8 Porter, R. W., Morius, H. J., and French, J. D., Surgery, St. Louis, 1953, 33, 875 .

${ }^{9}$ Croft, D. N., in Topics in Gastroenterology, ed. S. C. Truelove and D. P. Jewell, p. 58. Oxford, Blackwell, 1973. 